\title{
From Northern Ireland to Afghanistan: half a century of blast injuries
}

\author{
Ruth McGuire, ${ }^{1}$ A Hepper, ${ }^{1}$ K Harrison $^{2}$
}

'Dstl Porton Down, Salisbury, UK

${ }^{2}$ Ministry of Defence, Defence Statistics (Health), Bristol, UK

\section{Correspondence to} A Hepper, Platform Sciences, Dstl Porton Down, Salisbury SP4 0JQ, UK; aehepper@dstl.gov.uk

Received 23 November 2017 Revised 2 March 2018 Accepted 5 March 2018 Published Online First 26 May 2018
Check for updates

To cite: McGuire $R_{\text {, }}$ Hepper A, Harrison K. J R Army Med Corps 2019:165:27-32.

\begin{abstract}
Introduction Throughout the last half century, blast injuries have been a common occurrence to UK military personnel during combat operations. This study investigates casualty data from three different military operations to determine whether survivability from blast injuries has improved over time and whether the tactics used could have influenced the injuries sustained.
\end{abstract}

Methods Casualty data from operations in Northern Ireland, Iraq and Afghanistan were reviewed and found to contain a total of 2629 casualties injured by improvised explosive devices. The injury severities were examined and the suitability of comparison between conflicts was considered.

Results The case fatality rate and mean severity score sustained remained consistent among the operations included in this study. Using the New Injury Severity Score, the probabilities of survival were calculated for each separate operation. The body regions injured were identified for both fatalities and survivors. Using this information, comparisons of injury severities sustained at an Abbreviated Injury Scale of 3 and above (identified as a threshold for fatal injury) were conducted between the different operations.

Conclusions The data showed that as operations changed over time, survivability improved and the proportions of body regions injured also changed; however, this study also highlights how studying casualty data from different conflicts without taking account for the contextual differences may lead to misleading conclusions.

\section{INTRODUCTION}

Explosive devices have been one of the most common threats faced by UK military personnel in combat operations over the last half century causing a range of blast injuries (primary blast, fragmentation, displacement, impact and burn injuries). While many researchers examine one part of this spectrum of injuries (sometimes in isolation), we believe it is useful to use the improvised blast device as a common comparative threat to understand the commonality and differences between different military operations. The results should be used as a guide to consider whether the casualty data used in future studies may be comparable, especially when using casualty data across different conflicts.

The improvised explosive device (IED) has been the weapon of choice during asymmetric warfare, as opposed to those weapons employed by conventional military forces. During recent conflicts involving operations by the UK military in Northern Ireland (Operation BANNER), Iraq (Operation TELIC) and Afghanistan (Operation HERRICK),

\section{Key messages}

Casualty populations caused by improvised explosive devices (IED) in three recent largescale military operations have had fairly constant overall injury severities and case fatality rates.

- The survival rates of UK military personnel injured by IEDs have improved with time.

- Body regions injured by IEDs during different conflicts may not be comparable: this may be due to the device natures and the mitigation strategies.

- Users of casualty data from different conflicts must account for any differences in the threat, the way it is used or mitigating equipment/ tactics.

the use of IEDs became synonymous with the terrorist or insurgent activity being undertaken against the law enforcement authorities (including the military). The injurious impact of these devices is well documented in various reports. ${ }^{12}$

During these three recent operations 34\%, 38\% and $55 \%$ of reported casualties were injured in Operations BANNER, TELIC and HERRICK, respectively, by IEDs of one form or another. Detailed casualty data are also available for these operations, which facilitates comparison of the injury patterns and outcomes. This study has therefore used IEDs as the injury-causing threat for a comparison of casualties across multiple military operations.

The data available for this study cover the period of 1969-2013, which includes a period of significant medical care advances (including prehospital care availability and capability) ${ }^{34}$ and personal protective equipment (PPE) advances ${ }^{5-7}$ : the medical care advances may influence the outcome from a given injury, but the PPE influences the pattern of injuries sustained. ${ }^{8}$

The data come from the Hostile Action Casualty Survey (HACS) and the UK Joint Theatre Trauma Registry: two casualty databases that have been developed to allow for the examination of the injury patterns against different threats and different protective measures as well as for the audit of care. 910

The injuries sustained from an IED can be influenced by many factors (including size, composition, design and detonation method) and protective measures (PPE, whether mounted (on board a vehicle), dismounted (on foot) or using 
other mitigations). ${ }^{5-7}$ The purpose of this study was to investigate the comparability of IED incidents between the different operations and if survivability or injury profiles have changed over the last half century.

\section{METHOD}

The HACS $^{9}$ captured UK military personnel predominately injured by hostile means during Operation BANNER for the period from 1969 to 1997 . This system was developed to inform the medical provision in support of military operations during 'The Troubles' in Northern Ireland. Details of both the mechanism of injury and its anatomic classification were recorded.

Since 2003, UK military combat casualties have been recorded within the UK military Joint Theatre Trauma Registry (UK-JTTR), ${ }^{10}$ the Operational Emergency Department Attendance Register, ${ }^{11}$ field hospital admissions and notification of casualty system.

Within the Operations TELIC and HERRICK data sets, the injuries recorded in the UK-JTTR were coded by trauma nurse coordinators using the Abbreviated Injury Scale (AIS). ${ }^{12}$ Where sufficient data allowed in the other data sources data were retrospectively coded by a qualified AIS coder. AIS uses a 6-point severity scaling from 1-minor to 6-maximal. Using the injury data coded in AIS, the Maximum Abbreviated Injury Severity (MAIS) $^{12}{ }^{13}$ and the New Injury Severity Score (NISS) ${ }^{14}$ were calculated. ${ }^{\mathrm{i}}$ The MAIS is the most severe injury that a casualty sustains overall. The NISS uses the AIS severity score from the three most severe injuries that a casualty has sustained to calculate an overall injury severity. NISS is scored from 1, which signifies a minor injury, up to 75 , which represents an injury severity that would be expected to be incompatible with survival. NISS has been seen to be a more accurate predictor of mortality when compared with other, purely anatomical, injury scoring methods using AIS in various circumstances, ${ }^{15-17}$ although we appreciate there is some debate about its applicability to different types of trauma, ${ }^{18} 19$ and it is seen as inferior to methods that use physiological data (which are not available for these cohorts of patients). ${ }^{1620}$ We believe that for the purposes of this study the MAIS and NISS provide the most suitable measures for the comparisons of single-worst injury and multiply injured patients and are suitable for the purposes of this report.

\section{Comparative analysis}

The terminology used in casualty data reporting has changed over the data period investigated in this study. The terminology used to describe the threat type was the main area of ambiguity. In the Operation BANNER data the term 'bomb' or 'mine' (for a culvert emplaced device) was used to define devices that were improvised, that is, not conventional military ordnance. The term IED was used in more recent operational reporting and is a better description of the threat type. Therefore, we standardised the terminology across the data sets to ensure consistency.

In line with this study, the casualties reported as injured by an IED were identified within each data set; however, due to the hostile nature of the operational environment, it was not possible to fully investigate every incident. Therefore, there may be some ambiguity associated with the identification between some mines and IEDs (improvised devices were typically the home-made devices and mines were military ordnance): this

iThis study used values directly or calculated from the 2005 (update 2008) civilian Abbreviated Injury Scale. ${ }^{12}$
Table 1 UK military Ops BANNER, TELIC and HERRICK IED casualty overview

\begin{tabular}{|c|c|c|c|c|c|c|}
\hline & \multicolumn{2}{|c|}{ Op BANNER } & \multicolumn{2}{|l|}{ Op TELIC } & \multicolumn{2}{|c|}{ Op HERRICK } \\
\hline & Fatality & Survivor & Fatality & Survivor & Fatality & Survivor \\
\hline Number of casualties & 136 & 619 & 51 & 232 & 243 & 1348 \\
\hline Number of injuries & 1603 & 1817 & 408 & 684 & 3685 & 5435 \\
\hline $\begin{array}{l}\text { Mean number of } \\
\text { injuries }\end{array}$ & 11.8 & 2.9 & 8.0 & 2.9 & 15.2 & 4.0 \\
\hline $\begin{array}{l}\text { Range of number of } \\
\text { injuries }\end{array}$ & $1-43$ & $1-18$ & $1-20$ & $1-13$ & $1-57$ & $1-40$ \\
\hline Mean NISS & 57 & 5 & 61 & 6 & 61 & 9 \\
\hline
\end{tabular}

IED, improvised explosive device; NISS, New Injury Severity Score.

study therefore regards any explosive device emplaced by insurgents or terrorists as an IED.

Casualties were only included in this study if they had AIS-coded injuries that were adequately documented. The casualties from each operation were compared using MAIS and NISS to identify whether or not survival had improved over time.

In addition to considering the overall survivability, it was possible to consider whether the body regions injured during each operation had the potential to identify how the deployment of IEDs differed between the combat operations. Therefore, the body regions injured in each operation were identified, but only compared for people who sustained an injury of a severity where fatalities had occurred-this was to eliminate any confounding or skewing factors due to the possibility of high numbers of relatively minor injured personnel, but would account for any change in device severities between conflicts.

\section{RESULTS}

\section{Summary}

In the Operation BANNER HACS data set, 755 casualties were identified as injured by an IED. The case fatality ratio (CFR) was 0.18 (Table 1). The casualty cohort was $99 \%$ male, with a median age of 26 years (range 16-46).

The Operation TELIC data set reported 283 casualties who met the requirements for this study, which had a CFR of 0.18 (Table 1). The casualty cohort was $98 \%$ male with a median age of 25 years (range 18-42). Documented within the Operation HERRICK casualty data set were 1591 casualties injured by an IED with a CFR of 0.15 (Table 1). The casualty cohort was $99 \%$ male with a median age of 25 years (range 18-55). The proportion of casualties who died from their injuries during Operation BANNER to Operation HERRICK has therefore shown a slight decrease from 18\% in Operation BANNER and Operation TELIC to $15 \%$ in Operation HERRICK. The mean number of injuries has remained high, but given that this is reliant on consistent scoring, this is a poor indicator of injury level; however, the mean NISS of both the survivors and fatalities has increased through the conflicts. This is an indicator of improved survival, but can only really be considered when operational tempo and casualty treatment constraint are considered.

\section{Analysis of worst single injury}

The worst single injury for a casualty is the MAIS, which is the highest AIS severity that a casualty has sustained. The complete proportions of survivors and fatalities by MAIS are shown in

${ }^{\mathrm{ii}}$ The case fatality ratio is the proportion of casualties who died out of the total number of casualties who met the criteria (in this case the criterion for inclusion in this part of the study was sufficient detail in the injury data for comprehensively scored casualty records). 
Table 2 UK military Ops BANNER, TELIC and HERRICK MAIS by outcome

\begin{tabular}{|c|c|c|c|c|c|c|}
\hline & \multicolumn{2}{|c|}{ Op BANNER } & \multicolumn{2}{|c|}{ Op TELIC } & \multicolumn{2}{|c|}{ Op HERRICK } \\
\hline & $\begin{array}{l}\text { Fatality } \\
(\%)\end{array}$ & $\begin{array}{l}\text { Survivor } \\
(\%)\end{array}$ & $\begin{array}{l}\text { Fatality } \\
(\%)\end{array}$ & $\begin{array}{l}\text { Survivor } \\
(\%)\end{array}$ & $\begin{array}{l}\text { Fatality } \\
(\%)\end{array}$ & $\begin{array}{l}\text { Survivor } \\
(\%)\end{array}$ \\
\hline MAIS 1 & 0 & 100 & 0 & 100 & 0 & 100 \\
\hline MAIS 2 & 0 & 100 & 0 & 100 & 0 & 100 \\
\hline MAIS 3 & 13 & 87 & 11 & 89 & 1 & 99 \\
\hline MAIS 4 & 70 & 30 & 47 & 53 & 37 & 63 \\
\hline MAIS 5 & 93 & 7 & 95 & 5 & 83 & 17 \\
\hline MAIS 6 & 100 & 0 & 100 & 0 & 100 & 0 \\
\hline
\end{tabular}

MAIS, Maximum Abbreviated Injury Severity.

Table 2. This provides an overview of the maximum injury severities and survival rates for casualties by their single worst injury. This does not account for any cumulative effects of multiple injuries or treatment times and is a simplistic measure of severity.

During Operation BANNER, more than 1 in 10 casualties with a MAIS 3 died from their injuries, this decreased to 1 in 100 for Operation HERRICK: a reduction in fatalities at MAIS 3 of $92 \%$ (Table 2), that is, $92 \%$ of those who died during Operation BANNER with a MAIS of 3 would be expected to survive during Operation HERRICK, assuming all other aspects being equal (eg, there were no additional aspects during Operation BANNER that would have affected the availability of similar quality treatment). Similarly, the reduction in fatalities at MAIS
4 and 5 between Operations BANNER and HERRICK would be $46 \%$ and 11\%, respectively. Survivability at MAIS 6 has remained unchanged during this time, as expected for the unsurvivable nature of MAIS 6 coded injuries.

\section{New Injury Severity Score}

The mean NISS, as a measure of total trauma severity, sustained by casualties (Table 1) has remained consistent among the different operations, increasing by a maximum of 4 between Ops BANNER and HERRICK. Calculation of the probability of survival curve was undertaken using a bias-reduced generalised linear model ${ }^{21}$ : this was selected as it is reported as reducing the problem of separation within data, leading to a more accurate result when compared with other generalised linear model analysis methods. ${ }^{22}$ The probability of survivability curves is provided in Figure 1, indicating that survivability has improved between each of the combat operations. A 50\% chance of survival (as shown) was associated with a NISS of 29 for Operation BANNER, which rose to an NISS of 43 for Operation HERRICK. At the 95\% confidence level there is a statistically significant improvement in survival between Operation BANNER and Operation HERRICK.

\section{Injury location}

The percentage of casualties sustaining an injury to each body region for the three different operations was also determined (Table 3). This was to examine whether the body regions in the

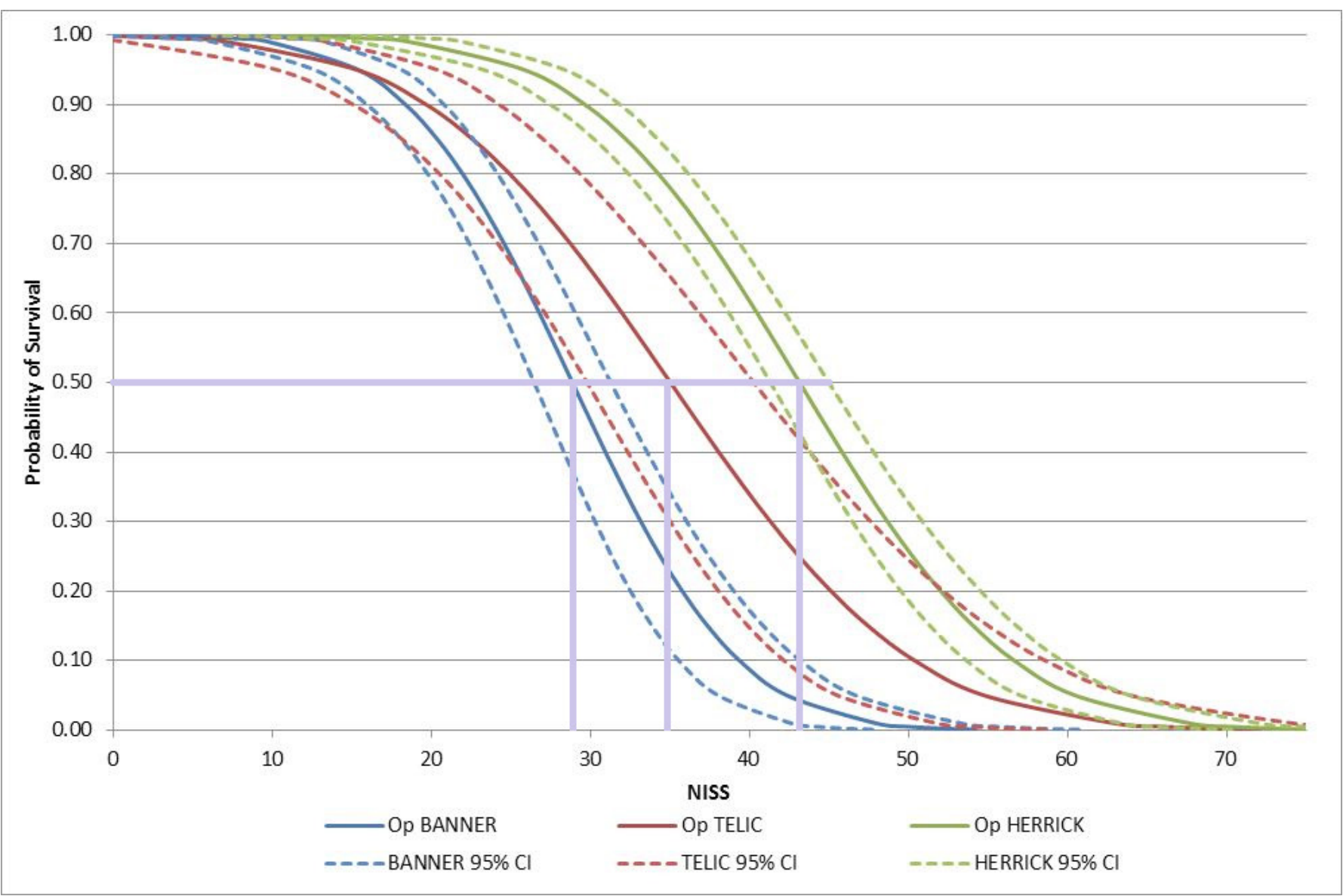

Figure 1 UK military Ops BANNER, TELIC and HERRICK improvised explosive device (IED) probability of survival (with 50\% probability of survival shown in purple). NISS, New Injury Severity Score. 


\begin{tabular}{|c|c|c|c|c|c|c|}
\hline & \multicolumn{2}{|c|}{ Op BANNER } & \multicolumn{2}{|c|}{ Op TELIC } & \multicolumn{2}{|c|}{ Op HERRICK } \\
\hline & $\begin{array}{l}\text { Fatality } \\
(\%)\end{array}$ & $\begin{array}{l}\text { Survivor } \\
(\%)\end{array}$ & $\begin{array}{l}\text { Fatality } \\
(\%)\end{array}$ & $\begin{array}{l}\text { Survivor } \\
(\%)\end{array}$ & $\begin{array}{l}\text { Fatality } \\
(\%)\end{array}$ & $\begin{array}{l}\text { Survivor } \\
(\%)\end{array}$ \\
\hline Head & 65 & 24 & 55 & 12 & 57 & 13 \\
\hline Face & 61 & 55 & 27 & 43 & 47 & 41 \\
\hline Neck & 27 & 5 & 37 & 8 & 30 & 7 \\
\hline Thorax & 63 & 11 & 61 & 9 & 64 & 9 \\
\hline Abdomen & 49 & 6 & 43 & 7 & 72 & 17 \\
\hline Spine & 19 & 3 & 33 & 4 & 37 & 13 \\
\hline $\begin{array}{l}\text { Upper } \\
\text { extremity }\end{array}$ & 58 & 35 & 29 & 41 & 63 & 44 \\
\hline $\begin{array}{l}\text { Lower } \\
\text { extremity }\end{array}$ & 66 & 43 & 35 & 36 & 81 & 54 \\
\hline Other trauma & 21 & 0 & 24 & 2 & 14 & 1 \\
\hline External & 18 & 5 & 18 & 14 & 7 & 6 \\
\hline
\end{tabular}

IED, improvised explosive device.

different conflicts were different and how the types of device may have affected injury profiles.

To account that some devices (or tactics) may cause many minor casualties that could skew the analysis, an analysis was conducted for those casualties that may have sustained a serious injury that could be fatal: AIS 3 and higher injuries were this threshold for fatal injury (Table 2). Casualties with an injury at AIS $\geq 3$ were identified by body region in the casualty cohort and the distribution of these injuries is provided in Table 4.

The applicability in this type of analysis can be seen by comparing the proportions of injuries from various body regions and how the proportions change with those with injuries when filtered (eg, the high percentage of arm injuries in the whole data reduces when filtered to people who have suffered and AIS 3 or higher injury). This should not be taken as hiding the severity or impact of these injuries to the individuals involved or that something could be done about these injuries.

Of significance in this analysis, the casualty data have identified that different patterns of injury have occurred during the various operations considered here (eg, the proportion of extremity and abdominal injuries was greater during Operation HERRICK than the other operations, the proportion of head injuries was greater during Operation BANNER and the

Table 4 UK military Ops BANNER, TELIC and HERRICK IED body regions injured at AIS 3, 4, 5 or 6 (as a proportion of total number in group)

\begin{tabular}{|c|c|c|c|c|c|c|}
\hline & \multicolumn{2}{|c|}{ Op BANNER } & \multicolumn{2}{|c|}{ Op TELIC } & \multicolumn{2}{|c|}{ Op HERRICK } \\
\hline & $\begin{array}{l}\text { Fatality } \\
(\%)\end{array}$ & $\begin{array}{l}\text { Survivor } \\
(\%)\end{array}$ & $\begin{array}{l}\text { Fatality } \\
(\%)\end{array}$ & $\begin{array}{l}\text { Survivor } \\
(\%)\end{array}$ & $\begin{array}{l}\text { Fatality } \\
(\%)\end{array}$ & $\begin{array}{l}\text { Survivor } \\
(\%)\end{array}$ \\
\hline Head & 60 & 4 & 49 & 4 & 48 & 3 \\
\hline Face & 4 & 0 & 10 & 0 & 11 & 0 \\
\hline Neck & 11 & 0 & 29 & 0 & 16 & 1 \\
\hline Thorax & 55 & 4 & 59 & 2 & 57 & 4 \\
\hline Abdomen & 31 & 0 & 27 & 1 & 57 & 3 \\
\hline Spine & 8 & 0 & 25 & 0 & 15 & 2 \\
\hline Upper extremity & 12 & 0 & 8 & 2 & 34 & 4 \\
\hline Lower extremity & 35 & 5 & 31 & 7 & 78 & 19 \\
\hline Other trauma & 21 & 0 & 8 & 0 & 14 & 0 \\
\hline External & 7 & 1 & 4 & 0 & 3 & 0 \\
\hline
\end{tabular}

AIS, Abbreviated Injury Scale; IED, improvised explosive device. proportion of neck and spinal injuries in fatalities was greatest during Operation TELIC-see Table 4). These patterns may not be as apparent in the data of all casualties (Table 3).

\section{DISCUSSION}

This study has focused on conducting a high-level analysis of UK military casualties injured by blast, and specifically IEDs, during three combat operations. Survivability and injury patterns have been used to investigate how improvements in survivability and injury patterns have changed when facing an IED threat. This is only a snapshot of the wealth of information that can be gleaned from cross-conflict data sets of casualties injured by the same mechanism.

The process of collecting and collating combat casualty data has changed considerably over the time period of this study, ${ }^{9-11}$ and is now seen as key evidence on the medical provision in the Defence Medical Services, as well as driving forward force protection improvements. ${ }^{4}$ Casualty data from Operation BANNER were collated more than 40 years after the campaign started. As a result of undertaking substantial verification and validation across all available data sources, the Operation BANNER data set is now thought to be comparable to the other operations in many respects; although some of the detail is missing for fatalities that may result in an underestimate of the CFR and an overestimate of survival probability for Operation BANNER.

At a high level it may appear that survivability has not improved (Table 1) between each operation since the CFRs are comparable; however, this metric does not take into account the severity, number, location or type of injury sustained. The proportion of casualties sustaining each MAIS by outcome (Table 2) has indicated how improvements in survivability have changed. Injuries with a maximum severity of AIS 1 or AIS 2 were individually survivable by casualties captured in the casualty data sets from each operation. The increase in survivability was particularly notable for casualties who sustained a maximum severity injury of AIS 3 or AIS 4, where survivability from Operation BANNER to Operation HERRICK has improved by $92 \%$ and $46 \%$, respectively. This compares to an $11 \%$ improvement for casualties with a MAIS 5. The improvement in survival is likely to be associated with advances in medical care such as wound management, pharmacological advances and the sophistication and availability of prehospital care, to mention a few. These aspects will all have had an influence on casualty outcome over the time period of this study. Using the data available, the individual effect of these advances cannot be fully identified or quantified and it is appreciated that the use of AIS is not a perfect tool because it cannot account in detail for the physiological condition of the casualty, nor the constraints on the medical care provision (timeliness or quality).

The types of IEDs, including the explosive component (mixture, size and the resulting fragmentation) used during each operation, were different. The nature of the devices, the nature of the tactics (patrol methods, patrol formats, and so on) and the types of mitigation are key to understanding the underlying issues: this highlights one of the difficulties with this type of comparative study and, as a result, extreme caution is recommended when comparing the data from different casualty-causing operations unless the underlying threat is understood.

The lower extremities were one such body region where differences were found for all injuries and injuries at a minimum of AIS 3. These can be attributed to two of the potential factors mentioned above, first was the mechanism 
of detonation of explosive devices: the method in which IEDs were deployed against dismounted personnel resulted in a high frequency of lower extremity injury, as the closest body part to the device it would be expected that this body region would sustain an injury. This could also be a contributing factor in the increase in abdominal injuries during Operation HERRICK despite the protection offered by thoracoabdominal body armour; however, further detailed analysis of the location within the abdomen is needed to identify the structures injured. The second factor was the proportion of casualties who were in a vehicle when injured. The higher proportion of face and neck injuries during Operation TELIC is likely influenced by the higher proportion of casualties injured while in a vehicle, with the additional protection it affords to the torso and legs. Mounted casualties in TELIC numbered 78\%, compared with $22 \%$ on Operation BANNER and $47 \%$ of Operation HERRICK. The IED type and mode of employment on Operation TELIC differed from those on Ops BANNER and HERRICK, as it was more of a focused, side-attack, antivehicle device rather than an antipersonnel device (Operations BANNER and HERRICK).

PPE is another factor which may have influenced the location of injuries sustained by combat personnel. The body armour worn during Ops TELIC and HERRICK was, in the main from 2006, the Osprey combat body armour (CBA) system. ${ }^{5}$ During Operation BANNER, CBA or enhanced CBA would have been the versions available. Further PPE developed at a rapid pace during Operation HERRICK in response to the threat and emerging injury trends; the introduction of protection systems, such as pelvic protection ${ }^{6}$ and the neck collar, ${ }^{7}$ may have also influenced the patterns of injury observed.

The body regions injured have identified how the different operations have different injury patterns and have a tactical element. This historical perspective has highlighted how injuries from the same 'mechanism' can differ depending on the factors of the combat operation. Therefore, focusing on a casualty cohort from a single operation may not be useful for future operational planning. Similarly, casualty data from different conflicts may not be appropriate to aggregate into a single population on the assumption that they are comparable without checking the operational context.

\section{CONCLUSIONS}

Combat casualty data from combat operations in Northern Ireland, Iraq and Afghanistan have been investigated to explore patterns in survivability and injury locations. Survivability has been found to have improved between combat operations in Northern Ireland starting in 1969 through to Afghanistan in 2013, assuming there were no operational constraints that affected the access of similar levels of medical care. An increase in survivability would be expected due to advances in medical care; however, this study has identified the extent of this improvement. Differences among the body regions injured have highlighted how the use of IEDs has changed over time and how tactics of device employment and defensive tactics may affect the injury profile.

This study highlights how having too strong a focus on injuries sustained in one operation, in isolation, has risks: any future operations where IEDs are a concern could reflect an injury pattern that is different from what has been seen in the recent operations. Similarly, the work highlights that data cannot simply be combined from different conflicts to end up with a single data set of apparently similarly injured personnel without factoring in the operational context. This work also highlights the need to be able to understand the threat, understand how tactics change the injurious effects and be able to react to these changes through the medical response and protective measures.

Contributors $\mathrm{AH}$ conceived the study. RM conducted the work with guidance from $\mathrm{AH}$ and $\mathrm{KH}$. The original data were collated by the Royal Centre for Defence Medicine, Academic Department of Military Emergency Medicine and RM. All authors have approved the final manuscript.

Funding This research received no specific grant from any funding agency in the public, commercial or not-for-profit sectors.

Competing interests None declared.

Patient consent Detail has been removed from this case description/these case descriptions to ensure anonymity. The editors and reviewers have seen the detailed information available and are satisfied that the information backs up the case the authors are making.

Provenance and peer review Not commissioned; externally peer reviewed.

(C) Crown copyright (2018), Dstl. This material is licensed under the terms of the Open Government Licence except where otherwise stated. To view this licence, visit or write to the Information Policy Team, The National Archives, Kew, London TW9 4DU, or email: psi@nationalarchives.gsi.gov.uk.

\section{REFERENCES}

1 Jacobs N, Rourke K, Rutherford J, et al. Lower limb injuries caused by improvised explosive devices: proposed 'Bastion classification' and prospective validation. Injury 2014:45:1422-8.

2 Morrison JJ, Hunt N, Midwinter M, et al. Associated injuries in casualties with traumatic lower extremity amputations caused by improvised explosive devices. $\mathrm{Br} \mathrm{J}$ Surg 2012;99:362-6.

3 Penn-Barwell JG, Roberts SA, Midwinter MJ, et al. Improved survival in UK combat casualties from Iraq and Afghanistan: 2003-2012. J Trauma Acute Care Surg 2015;78:1-1020

4 Bricknell MCM, Nadin M. Lessons from the organisation of the UK medical services deployed in support of Operation TELIC (Iraq) and Operation HERRICK (Afghanistan). $J$ R Army Med Corps 2017:163:273-9.

5 Lewis E. Between Iraq and a hard plate: recent developments in UK military personal armour. Paper 28, 8th Personal Armour Systems Symposium (PASS. Leeds, UK: The Royal Armouries Museum, 2006:19-22.

6 Lewis EA, Pigott MA, Randall A, et al. The development and introduction of ballistic protection of the external genitalia and perineum. J R Army Med Corps 2013;159:115-7.

7 Breeze J, Allanson-Bailey L, Hunt N R, et al. Development of the new ballistic neck collar to protect UK soldiers from explosive fragmentation injury in Afghanistan: personal armour systems symposium. 2014.

8 Dismounted Complex Blast Injury Task Force. Dismounted complex blast injury: report of the army dismounted complex blast injury task force. 2011. http://armymedicine. mil/Documents/DCBI-Task-Force-Report-Redacted-Final.pdf (accessed 01 Jun 2015)

9 Owen-Smith MS, Lecture H. Hunterian Lecture 1980: a computerised data retrieval system for the wounds of war - the Northern Ireland Casualties.J R Army Med Corps 1981:127:31-54

10 Smith J, Hodgetts T, Mahoney P, et al. Trauma governance in the UK defence medical services. J R Army Med Corps 2007;153 239-42. Discussion 43.

11 Russell R, Hodgetts T, Ollerton J, et al. The operational emergency department attendance register (OPEDAR): a new epidemiological tool. J R Army Med Corps 2007; $153: 244-50$

12 AAAM. The Abbreviated Injury Scale 2005. Des Plaines, Illinois: AAAM, 2008.

13 Gennarelli TA, Wodzin E AIS. A contemporary injury scale. Injury 2005;2006:1083-91.

14 Osler T, Baker SP, Long W. A modification of the injury severity score that both improves accuracy and simplifies scoring. J Trauma 1997;43:922-6.

15 Lavoie A, Moore L, LeSage N, et al. The new injury severity score: a more accurate predictor of in-hospital mortality than the Injury Severity Score. J Trauma 2004;56:1312-20

16 Hannan EL, Waller CH, Farrell LS, et al. A comparison among the abilities of various injury severity measures to predict mortality with and without accompanying physiologic information. J Trauma 2005:58:244-51.

17 Harwood PJ, Giannoudis PV, Probst C, et al. The polytrauma group of the german trauma society, which AIS based scoring system is the best predictor of outcome in orthopaedic blunt trauma patients. J Trauma 2006;60:344-340.

18 Stephenson SC, Langley JD, Civil ID. Comparing measures of injury severity for use with large databases. J Trauma 2002;53:326-32.

19 Tohira H, Jacobs I, Mountain D, et al. Systematic review of predictive performance of injury severity scoring tools, Scandinavian Journal of Trauma. Resuscitation and Emergency Medicine 2012;20:63 
20 Wong TH, Krishnaswamy G, Nadkarni NV, et al. Combining the new injury severity score with an anatomical polytrauma injury variable predicts mortality better than the new injury severity score and the injury severity score: a retrospective cohort study. Scand I Trauma Resusc Emerg Med 2016;24:25.
21 Kosmidis I. brglm: Bias Reduction in Binomial-Response Generalized Linear Models, Computer programme. R Package 2013.

22 Ellis S, Mansson R, Craddock L, et al. Design and analysis of binary trials. The Institute of Mathematics \& its Applications Conference. Malvern, UK: Mathematics in Defence QinetiQ, 2013. 